\title{
INSERÇÃO DE SIMULAÇÕES DE DESEMPENHO TÉRMICO NO PROCESSO DE PROJETO
}

\author{
INSERTION OF THERMAL PERFORMANCE SIMULATIONS IN THE DESIGN PROCESS
}

\author{
(D) Larissa Pereira de Souza ${ }^{1}$ \\ (D) Mateus Vinícius Bavaresco ${ }^{2}$ \\ Carlos Eduardo Verzola ${ }^{3}$ \\ (D) Roberto Lamberts 4 \\ 1 Universidade Federal de Santa Catarina, \\ Florianópolis, SC, Brasil, \\ laripereiradesouza@gmail.com \\ 2 Universidade Federal de Santa Catarina, \\ Florianópolis, SC, Brasil, \\ bavarescomateus@gmail.com \\ 3 Universidade Federal de Santa Catarina, \\ Florianópolis, SC, Brasil, \\ cevvoo@gmail.com \\ 4 Universidade Federal de Santa Catarina, \\ Florianópolis, SC, Brasil, \\ roberto.lamberts@ufsc.br
}

Contribuição dos autores:

LPS: conceituação, curadoria de dados, análise formal, investigação, metodologia, administração de projetos, validação, visualização, escrita - rascunho original, escrita - revisão e edição. MVB: análise formal, investigação, metodologia, validação, escrita - rascunho original, escrita - revisão e edição. CEVV: conceituação, investigação, metodologia, supervisão, validação, escrita - rascunho original, escrita - revisão e edição. RL: conceituação, investigação, metodologia, administração de projetos, supervisão, validação, escrita - rascunho original, escrita - revisão e edição.

Fomento: Coordenação de Aperfeiçoamento de Pessoal de Nível Superior

Declaração de conflito: nada foi declarado.

Editor(es) Responsável:

Vanessa Gomes da Silva (D)

\begin{abstract}
Resumo
O crescente aumento de consumo energético em edificações é uma questão preocupante. $O$ modo como as edificações se comportam em relação ao clima em que estão inseridas é importante no seu consumo final, e assim, diretrizes iniciais de projeto voltadas ao seu comportamento térmico podem reduzir boa parte do consumo durante a operação. Isso porque essas diretrizes visam otimizar o desempenho das edificações, minimizando o uso de equipamentos de resfriamento para garantir o conforto dos usuários. No entanto, essas análises de desempenho térmico são realizadas com o projeto já consolidado, dificultando o alcance de bons níveis de desempenho e sem grande margem de alteração de projeto com este foco. Visando unir o processo a essas análises, o objetivo deste trabalho é o levantamento de dados sobre o processo de projeto de arquitetos para compreender quais parâmetros de desempenho já são considerados, quais outros poderiam ser incorporados, e quais as fases de maior relevância do ponto de vista térmico. Percebeu-se que os participantes deste estudo, apesar de considerarem relevante a avaliação de critérios como insolação e ventilação natural na concepção de projeto, o fazem com métodos pouco precisos. Além disso, evidenciou-se o desconhecimento de aspectos importantes, como a NBR 15575, a etiqueta de eficiência energética e o uso de simulações computacionais. Portanto, propõe-se uma estrutura de trabalho integrando as respostas sobre definições de projeto com os critérios de análise de desempenho. $O$ desenvolvimento de uma estrutura de trabalho permitirá futuros experimentos de inserção de simulações no processo de projeto para validação.
\end{abstract}

Palavras-chave: Processo de projeto. Definição de parâmetros. Estrutura de trabalho. Simulação de edificações. Desempenho térmico.

\begin{abstract}
The increasing energy consumption in buildings is a matter of concern. How buildings behave concerning the weather is important regarding their final consumption since initial design guidelines can reduce future consumption projection. These guidelines seek to optimize the thermal performance of the building by reducing cooling needs and, at the same time, keeping indoor temperatures passively. However, thermal performance analyses are performed in late design, making it difficult to achieve good performance levels without much room for project change. Aiming to unite the process to these analyses, the objective of this work is to collect data about the architects' design process and create a framework. Also, to understand which performance parameters are already considered in the design process, which others could be and which design phases in which the project definition parameters have greater relevance from a thermal performance perspective. Despite considering the evaluation of criteria such as natural lighting and ventilation to be relevant in the design, the participants in this study do so with inaccurate methods. Besides, there was a lack of knowledge of important aspects, such as NBR 15575, the energy efficiency label, and computer simulations. From these results, a framework is proposed to facilitate the integration between the two studies, in which thermal performance simulations are embedded in the design process. Furthermore, the framework allows future experiments, including thermal performance simulations, to validate its design process.
\end{abstract}

Keywords: Design process. Parameter setting. Framework. Building simulation. Thermal performance.

How to cite this article:

PEREIRA DE SOUZA, L.; BAVARESCO, M. V.; VAZ, C. E. V.; LAMBERTS, R. Inserção de simulações de desempenho térmico no processo de projeto. PARC Pesquisa em Arquitetura e Construção, Campinas, SP, v. 12, p. e021011, 2021. DOI: http://dx.doi.org/10.20396/parc.v12i00.8657346 


\section{Introdução}

O constante aumento de consumo energético em edificações vem preocupando profissionais de diversas áreas do conhecimento. Um dos principais motivos para isto é o crescimento no consumo de condicionamento de ar a nível mundial, visto que as vendas anuais desses aparelhos quase quadriplicaram entre 1990 e 2016. Além disso, considerando-se o cenário mundial, projeções apontam que o consumo energético para resfriamento pode triplicar até 2050 (IEA, 2018). No Brasil, o consumo energético das edificações, além de expressivo, também apresenta crescimento. De acordo com o EPE (2019), os consumos dos setores comerciais e residenciais aumentaram mais de $40 \%$ entre 2008 e 2017.

A fim de amenizar o aumento de consumo energético por resfriamento, é necessário adequar as edificações aos climas em que serão inseridas. Neste sentido, diretrizes iniciais de projeto podem reduzir boa parte da projeção futura, considerando que estas podem ser medidas passivas para manter condições térmicas confortáveis nos ambientes internos. Sabe-se que parâmetros importantes para o desempenho térmico de edificações começam a ser definidos em fases iniciais de projeto, ou seja, são os projetistas os maiores responsáveis por essas escolhas. Ainda que sejam tomadas decisões importantes quanto às características da envoltória da edificação desde a sua concepção, a efetividade destas diretrizes em relação ao consumo final de resfriamento precisa ser avaliada com rigor técnico e métodos confiáveis. Afinal de contas, aspectos específicos relacionados ao local de implantação ou aos usos finais, por exemplo, podem comprometer a eficácia de estratégias inicialmente consideradas positivas.

Infelizmente, a maior parte da preocupação com o desempenho térmico final da edificação ocorre em fases mais avançadas do projeto. Nestas fases não é realizar alterações expressivas em parâmetros chave no desempenho térmico da edificação, como aspectos da volumetria, orientações solares dos ambientes, localização em relação ao entorno, dimensões de aberturas, entre outros. Assim, as medidas tomadas em fases posteriores dependem de materiais e tecnologias mais avançadas, e consequentemente, resultam em custos mais elevados (AIA, 2019; NEMBRINI; SAMBERGER; LABELLE, 2014; SAMUELSON et al., 2016).

Isso enfatiza a importância que se deve dar para o desempenho térmico da edificação em fases iniciais de projeto. No entanto, nota-se que há distanciamento do desenvolvimento de projeto e das análises de desempenho térmico de edificações tanto no meio acadêmico quanto no mercado de trabalho. É evidente que ambos estão relacionados, visto que havendo a fragmentação do ensino de projeto e o de desempenho térmico durante a formação dos projetistas, o método de desenvolvimento de projeto durante a carreira profissional dificilmente levará em consideração aspectos de desempenho térmico dos ambientes projetados. (BLEIL DE SOUZA; TUCKER, 2013)

Apesar da potencialidade do uso de ferramentas computacionais para a integração de critérios de desempenho térmico durante o processo de projeto, algumas dificuldades ainda precisam ser superadas. A interoperabilidade entre programas de desenvolvimento de projeto e de simulações de desempenho, por exemplo, ainda é distante. Isso porque as ferramentas não são desenvolvidas de forma interdisciplinar, e consequentemente, não são facilmente inseridas no processo criativo. Consequentemente, o conhecimento sobre simulação do desempenho térmico das edificações demanda muito tempo, tanto das variáveis inseridas e posteriormente analisadas, quanto da ferramenta que realiza essas simulações (ØSTERGÅRD; JENSEN; MAAGAARD, 2016). 
Independentemente das dificuldades que esta área ainda enfrenta, reforça-se que as simulações são importantes visto a necessidade de compreender se a diretriz de projeto tomada anteriormente realmente está funcionando como esperado.

A partir dos pontos anteriores, questiona-se quão difundidos estão esses conhecimentos específicos por parte dos arquitetos. Considerando o distanciamento entre os ensinos de projeto e de desempenho térmico do ambiente construído, percebe-se que os métodos de projeto adotados atualmente tendem a desconsiderar aspectos relevantes sobre o desempenho das edificações (BLEIL DE SOUZA; TUCKER, 2013). Portanto, questiona-se se a boa interoperabilidade entre programas de análise de desempenho e de desenvolvimento de projeto poderia facilitar a integração destes assuntos, podendo futuramente ser incorporada no ensino de projeto. (ØSTERGÅRD; JENSEN; MAAGAARD, 2016). Havendo integração entre os temas e programas utilizados, estas ferramentas poderiam guiar o projetista na melhoria do desempenho do edifício a partir das análises realizadas, evitando perda de tempo com cálculos e com diretrizes que, na verdade, podem não funcionar como esperado (AIA, 2019).

Contudo, é importante compreender se a inserção de simulação, a fim de guiar a melhoria no desempenho de projeto durante o andamento de projeto, é de interesse dos arquitetos. Além disso, questionam-se quais seriam suas preferências em relação à integração e à análise de resultados, caso desejável. Ao mesmo tempo, compreender os conhecimentos já adquiridos por eles e quais são realmente incorporados nos seus projetos. Tendo em vista os pontos anteriormente citados, a presente pesquisa tem como objetivo principal o levantamento de dados sobre o processo projetual de arquitetos brasileiros inseridos no mercado de trabalho atual. A partir deste levantamento, busca-se compreender quais parâmetros de desempenho já são considerados por estes durante seu método de desenvolvimento de projeto, quais outros poderiam ser incorporados segundo seu interesse, e mais importante, quais as fases em que os parâmetros de projeto necessários à simulação têm maior relevância. Baseando-se neste levantamento, relacionam-se as definições de projeto com os critérios de análise de desempenho térmico de edificações para que então seja proposta uma estrutura de trabalho a partir dos resultados obtidos, com o intuito de facilitar a integração entre os dois estudos.

\section{Fundamentação}

A revisão teórica deste estudo está dividida entre as pesquisas relacionadas ao desenvolvimento de projeto e as que englobam simulação de desempenho térmico. Por fim, relacionam-se estas duas áreas para o desenvolvimento do método.

\section{Processo de projeto}

Os estudos sobre o desenvolvimento de projeto dos arquitetos englobam diversas problemáticas e subjetividades. Inicialmente, este processo não pode ser definido como linear, tendo em vista as atividades cognitivas complexas dos projetistas. A definição deste processo passa a ser, na realidade, uma descrição dos produtos gerados pelo seu desenvolvimento. Alguns autores concordam que o projeto é desenvolvido a partir da busca de problemas e das suas respectivas soluções. Sendo assim, desde o início deste processo até a verificação da decisão, são observados os estágios de análise, síntese e avaliação e é durante esses estágios que as decisões de projeto são tomadas. Para isto, a avaliação final, ou decisão de projeto, é analisada a partir de critérios como coerência da solução encontrada com o projeto proposto; a viabilidade desta em relação ao projeto; e por fim, a valoração, ou seja, uma análise mais subjetiva no que diz respeito à satisfação com a solução gerada (MITCHELL, 2009; LAWSON, 2011). 
Os avanços tecnológicos nos últimos anos mostraram a busca pelo aumento da produtividade no processo de projeto. Esse avanço permite a diminuição no tempo de trabalho na geração de soluções, anteriormente dificultado pelos métodos analógicos de desenvolvimento, que inviabilizavam grandes alterações e geração de diversas soluções para problemas variados. Com a melhoria na tecnologia e maior número e capacidade de métodos digitais, há maior rapidez do raciocínio, e consequentemente, mais problemas, de âmbitos diferentes, podem ser incorporados (MITCHELL, 2009).

$\mathrm{Na}$ busca pelo entendimento do processo, Lawson (2011) defende que os estudos experimentais de observação e acompanhamento do andamento do projeto não condizem com o seu verdadeiro desenvolvimento. O autor acredita que, ao ser analisado, o projetista se porta de forma diferente do habitual e, consequentemente, não realiza o seu projeto de forma natural.

Seguindo este raciocínio, considera-se aqui o Hawthorne effect, que é o estudo no qual mostra que os participantes de um experimento mudam seus comportamentos quando são observados em suas tarefas, seja consciente ou inconscientemente (CHERRY, 2020). Deste modo, conclui-se que entrevistas e questionários são mais interessantes para este levantamento, uma vez que a probabilidade de veracidade nas respostas é maior que o método de observação. Mesmo que, segundo Lawson (2011), os entrevistados por meio de questionários tendam a recordar do processo de forma mais racional do que ocorre, vê-se esse levantamento como mais próximo ao real. Além disso, entrevistas e questionários permitem maior coleta de dados, maior abrangência e que profissionais imersos no mercado participem, em vez de experimentos de observação que são realizados com estudantes em sua grande maioria.

Em relação à apresentação do projeto e ao seu nível de evolução, o Instituto dos Arquitetos do Brasil considera as fases de projeto a partir de suas etapas principais: etapas preliminares, que consistem na coleta de informações, no programa de necessidades e no estudo de viabilidade; etapas de projeto, que englobam desde o estudo preliminar, anteprojeto até a coordenação de compatibilizações; e etapas complementares ao projeto, que comportam as assessorias de aprovação e assistências à execução (CAU/BR, 2014).

Por fim, é possível relacionar as duas áreas: processo cognitivo e gestão de projeto. Ainda que as duas sejam bem diferentes em conteúdo, ambas estão intimamente ligadas. De um lado, os processos cognitivos são responsáveis pelas tomadas de decisões a partir de avaliações e refinamento das soluções encontradas, e do outro, a gestão e organização do projeto cria certa linearidade e fluxo de trabalho e assim traçam-se os objetivos. Nota-se a linearidade da organização do método de gestão e desenvolvimento de projeto, mas essa linearidade segue na determinada direção partindo das constantes avaliações de soluções do processo.

\section{Simulações de desempenho térmico}

Edificações de alto desempenhos são comumente associadas à utilização de materiais e composições (vidros, paredes e coberturas) de tecnologia avançada, e por conseguinte, valor elevado. Mas isso ocorre devido à preocupação tardia com o desempenho térmico do edifício projetado, considerando que este não é um objetivo traçado desde o início do seu desenvolvimento, e assim, alguns ajustes impactantes no desempenho não podem mais ser realizados, como a definição volumétrica.

Se incorporados desde o início, os conceitos de bioclimatologia podem levar a edificação à melhoria no desempenho em geral. Por bioclimatologia na arquitetura entende-se evitar ou usufruir de condições do clima para a qualidade do ambiente 
interno. Ao estudar o clima, entendem-se as diretrizes interessantes para aquele local, seja aproveitar ou barrar o vento e o sol na edificação. Como ressalta Maciel (2006), a arquitetura bioclimática é um pacote adicional à edificação, geralmente não incorporada ao projeto como diretriz na concepção. A autora enfatiza a importância de compreender o processo de projeto para que sejam identificados os elementos relacionados a conceitos bioclimáticos. Há, porém, grande dificuldade em levantar quais são as eventuais barreiras na implementação destas diretrizes durante o processo. Para se alcançar um edifício de alta performance e qualidade é necessário focar primeiramente em estratégias passivas, e ainda assim, é imprescindível o uso de simulações de desempenho do edifício para a otimização das estratégias adotadas e de seus custos.

Por conseguinte, incorporar as simulações de desempenho no processo de projeto é de grande importância, não só para os escritórios, mas também para os clientes e futuros usuários do edifício, uma vez que os ambientes passam a ser mais confortáveis em diversos âmbitos. Para os projetistas, estas simulações podem guiar a tomada de decisões visando redução de consumos finais da edificação. Para os clientes, isso impacta nos custos iniciais e operacionais do edifício. Por exemplo, ao minimizar a incidência de radiação solar direta em um ambiente inserido em um clima quente, evitase maior necessidade de uso de equipamentos de condicionamento de ar para refrear o superaquecimento dos ambientes. Ainda assim, estudar as diretrizes ideais para cada clima é um pouco complexo e pode, algumas vezes, não resultar no esperado (AIA, 2019).

Para tanto, é importante reforçar o método de simulação como uma ferramenta que auxilia no processo projetual, melhorando a escolha e o refinamento de decisões de projeto baseado no melhor desempenho térmico. Infelizmente, o distanciamento entre o conhecimento sobre desempenho e projeto se nota também ao perceber a falta de ferramentas computacionais que auxiliem no entendimento dos fenômenos físicos da edificação. Desta forma, projetistas são forçados a se basearem em conhecimentos próprios e analógicos para prever consequências das decisões de projeto tomadas.

Estes pontos demonstram a necessidade de um método mais efetivo que integre simulações de desempenho térmico no desenvolvimento de projeto. Tendo em vista não somente a união para o processo, mas para o próprio ensino de projeto, incentivando a incorporação recorrente do projetista em sua carreira. (AIA, 2019; BLEIL DE SOUZA, 2013).

Ao considerar um método digital de análise de desempenho térmico de edificações, tal como as simulações termo-energéticas, agrega-se esta análise ao processo de projeto também digital. Nota-se grande potencial de união entre as duas áreas de forma deliberadamente sutil. Assim, a busca por resolução de problemas, encontradas sempre no processo de projeto, pode ser reduzida e facilitada se considerar as análises de diretrizes bioclimáticas de projeto analisadas por meio de simulações termoenergéticas, e não por embasamento empírico.

Apesar da união entre ferramentas digitais de projeto e de simulação terem grande potencial para a solução desta conexão, a interoperabilidade entre estes passa a ser o problema. Ressalta-se que o desenvolvimento destas ferramentas de simulação não é interdisciplinar. Sendo assim, arquitetos e projetistas não fazem parte do desenvolvimento de ferramentas de simulação, e por conseguinte, os programas resultantes não são facilmente aplicáveis ao seu processo criativo.

Parâmetros de projeto que são importantes para a simulação de desempenho podem não estar intrinsecamente ligados às definições iniciais de projeto. Assim como as 
simulações não permitem dados de entrada padrão para algumas indefinições iniciais de projeto e, novamente, impossibilita análises. Ainda se considerasse que estes parâmetros de projeto e de entrada de simulações fossem congruentes, os dados de saída das simulações são complexos e a sua posterior análise para a proposição de soluções não é intuitiva e facilmente aplicada à solução de projetos (BLEIL DE SOUZA, 2013; ELBELTAGl et al., 2017).

Ao analisar a disponibilidade de programas, notam-se diferentes motores de simulação de desempenho térmico em edificações. $O$ mais comumente utilizado em estudos e desenvolvimento de ferramentas integradas é o EnergyPlus ${ }^{1}$, que simula o consumo de energia de edifícios, desde consumo para aquecimento, resfriamento, ventilação, iluminação e cargas internas, até uso de água e geração de energia. Esta simulação é baseada em cálculos de interações entre o ambiente interno e externo da edificação, sendo assim, necessita de informações de ambos os meios. No caso do meio externo, a simulação opera por meio de arquivos climáticos, que são arquivos com informações de radiação, ventilação, temperaturas, nebulosidade, entre outros, de determinada cidade ou local. Já a definição do meio interno depende das definições de projeto, que no caso da simulação, são itens como as dimensões da volumetria (janelas, paredes, pé direito), orientação solar, propriedades dos materiais utilizados, potência dos equipamentos e de iluminação, número de pessoas e padrão de uso e ocupação de todos os ambientes. Alguns dados de entrada podem ser padrões por tipos de uso da edificação (escola, hotel, residencial, entre outros), ou seja, o programa disponibiliza alguns defaults (SHI et al., 2016).

O EnergyPlus serve de motor para o desenvolvimento de diversas ferramentas de simulação, aplicadas a um software atrelado ao processo de projeto ou não. Para tanto, existem pontos importantes que devem ser analisados ao se escolher o software de simulação no processo de projeto: a facilidade de uso, o tempo e custo de utilização, o nível de interoperabilidade com programas de modelagem (com o objetivo de interoperabilidade imperceptível), dados de entrada necessários (se possui dados padrões para parâmetros ainda não definidos), dados de saída (facilidade de compreensão dos resultados para a tomada de decisões) e a precisão da ferramenta. Sendo assim, é importante ter conhecimento das fases do projeto que esta ferramenta pode ser aplicada, quão modificável ela é e sua capacidade de visualização de resultados (AIA, 2019).

Tendo em vista as diversas etapas de projeto apontadas anteriormente, consideraramse para este estudo as etapas mais efetivas na definição de parâmetros. Então, as etapas preliminares, que estão relacionadas à concepção de projeto, e a etapa de projeto, na qual encontra-se o estudo preliminar e o anteprojeto, ainda na definição e no refinamento das informações, foram incorporadas para este levantamento. Isso porque poucas alterações relevantes em relação às características volumétricas e projetuais da edificação são realizadas nas fases posteriores.

Da mesma forma, nota-se que o levantamento destes dados se dá melhor por meio de questionários ou entrevistas. Isto tendo em vista a maior possibilidade de abrangência, a velocidade de resposta, a facilidade de tratamento de dados posteriormente e a maior proximidade com a veracidade dos resultados coletados por meio desse método, como já apontado anteriormente por Lawson (2011).

\section{Método}

Para o levantamento dos dados de projeto e sua relação com as definições de diretrizes bioclimáticas e de desempenho, dividiu-se o estudo em três etapas principais: a 
aplicação de questionário a arquitetos inseridos no mercado de trabalho, a análise e relação dos resultados obtidos por essa aplicação e, por fim, a proposição para uma estrutura de trabalho com avaliações de desempenho inseridas no desenvolvimento de projeto.

\section{Levantamento de dados por meio de questionário}

O desenvolvimento do questionário contou com uma aplicação piloto em alguns estudantes de arquitetura e arquitetos, a fim de aperfeiçoar os questionamentos e refinar sua aplicação. A partir de respostas obtidas, desenvolveu-se o questionário deste estudo, aplicado a outros arquitetos de todo o Brasil. Aplicou-se de forma online, a fim de evitar constrangimentos, permitir a desistência do entrevistado durante as respostas, e abranger diferentes regiões brasileiras para aumentar as taxas de resposta. O questionário ${ }^{2}$ foi aprovado pelo Comitê de Ética em Pesquisa com Seres Humanos CEPSH/UFSC.

O envio do questionário se deu via e-mail para preenchimento online. Foram mais de 500 envios para diversos escritórios e profissionais autônomos de todas as capitais brasileiras. A disponibilidade para preenchimento foi de 10 semanas, e nesse período, foram levantadas 72 respostas (taxa de resposta de aproximadamente 14,4\%).

O questionário se divide em três seções principais: as definições de projeto, a consideração de parâmetros bioclimáticos e de desempenho térmico no processo e, por fim, a possibilidade de incorporar simulação de desempenho térmico. As fases de projeto levantadas para todas as perguntas são: concepção, estudo preliminar e anteprojeto, a partir das considerações anteriores. Para cada um dos parâmetros questionados, foi possível selecionar uma ou mais fases de projeto em que este era mais relevante segundo suas definições. Os parâmetros levantados são apresentados no Quadro 1.

\begin{tabular}{|c|c|c|}
\hline Seção do questionário & Descrição & Dados \\
\hline \multirow{2}{*}{ Definições de projeto } & Parâmetros de projeto & $\begin{array}{l}\text { Volumetria, análise do entorno, materiais, cores, orientação, número de ambientes, } \\
\text { dimensões dos ambientes, pé direito, elemento de sombreamento, localização das } \\
\text { aberturas, tamanho das aberturas, iluminação artificial, acessos, legislação }\end{array}$ \\
\hline & $\begin{array}{l}\text { Métodos de } \\
\text { desenvolvimento de projeto }\end{array}$ & $\begin{array}{c}\text { Anotações escritas, croquis, maquetes físicas, prototipagem, CAD (autocad, } \\
\text { microstation), modelagem 3D (SketchUp), Formit/Revit, ArchiCAD, Rhinoceros, } \\
\text { Rhinoceros+Grasshopper }\end{array}$ \\
\hline \multirow[t]{2}{*}{$\begin{array}{l}\text { Parâmetros bioclimáticos } \\
\text { considerados* }\end{array}$} & $\begin{array}{l}\text { Diretrizes bioclimáticas e de } \\
\text { desempenho }\end{array}$ & $\begin{array}{c}\text { Insolação/sombreamento, iluminação natural, ventilação natural, iluminação artificial, } \\
\text { projeto de ar condicionado, cores, materiais (isolamento, inércia térmica entre outros), } \\
\text { análise da norma de desempenho NBR15575, etiqueta de eficiência, simulação de } \\
\text { consumo }\end{array}$ \\
\hline & $\begin{array}{l}\text { Métodos de teste das } \\
\text { diretrizes }\end{array}$ & $\begin{array}{l}\text { Não considero, manualmente, SketchUp, programas BIM, parametrização } \\
\text { (Rhinoceros+Grasshopper), softwares de simulação (EnergyPlus, Radiance, entre outros) }\end{array}$ \\
\hline \multirow{5}{*}{$\begin{array}{l}\text { Incorporação de } \\
\text { simulação** }\end{array}$} & $\begin{array}{l}\text { Consideraria mais } \\
\text { parâmetros se a informação } \\
\text { fosse facilmente acessível? }\end{array}$ & $\begin{array}{l}\text { 1. Não, acho que já considero o suficiente } 2 \text {. Não, não acho importante } 3 \text {. Sim, mas não } \\
\text { tenho muito conhecimento no tema } 4 \text {.Sim, mas acho a informação de difícil } \\
\text { compreensão } 5 \text {. Sim, pois tenho interesse em me atualizar no tema }\end{array}$ \\
\hline & $\begin{array}{l}\text { Preferência pela ferramenta } \\
\text { de simulação }\end{array}$ & Integrada ou externa ao ambiente de modelagem \\
\hline & $\begin{array}{l}\text { Qual resultado de maior } \\
\quad \text { interesse? }\end{array}$ & $\begin{array}{l}\text { Temperatura interna do ambiente, trocas de calor das superfícies (paredes e janelas), } \\
\text { concordância com a norma de desempenho NBR15575, graus-hora de desconforto, } \\
\text { carga térmica de aquecimento e resfriamento, consumo de ar condicionado, consumo } \\
\text { total, classificação da etiqueta de eficiência energética }\end{array}$ \\
\hline & $\begin{array}{l}\text { Como gostaria de analisar } \\
\text { os resultados? }\end{array}$ & $\begin{array}{l}\text { Por diferenciação de cores da volumetria, por uma escala comparativa, por escala } \\
\text { gráfica de eficiência/consumo, por gráficos com variação anual, com uma escala } \\
\text { comparativa, numericamente }\end{array}$ \\
\hline & $\begin{array}{l}\text { Como tomar decisões e } \\
\text { fazer alterações no projeto, } \\
\text { com os resultados } \\
\text { anteriores? }\end{array}$ & $\begin{array}{l}\text { Falar com um especialista, receber uma resposta do programa (quais alterações } \\
\text { tornariam o projeto mais eficiente), não preciso de ajuda }\end{array}$ \\
\hline
\end{tabular}

Nota: $\left({ }^{*}\right)$ adicionada a opção de não considerar algum parâmetro $\left({ }^{* *}\right)$ adicionadas as opções de não saber analisar o dado ou de não ter interesse neste. Fonte: os autores. 
O questionário foi elaborado considerando a necessidade de minimizar o viés da desejabilidade social, que consiste na tendência dos entrevistados responderem o que acreditam ser socialmente desejável e não coerente com a sua realidade. Ao incluir uma pergunta sobre quais parâmetros bioclimáticos são considerados e correlacioná-los com outra questão sobre o método de avaliação da eficácia destas diretrizes é possível triangular as respostas e determinar a efetividade destas considerações.

\section{Análise dos resultados}

Após o preenchimento do questionário, as respostas foram analisadas de forma quantitativa. Os critérios principais para a avaliação foram as relações entre:

i. os parâmetros bioclimáticos já abordados no desenvolvimento do projeto e como os projetistas testam a efetividade da diretriz tomada;

ii. o conhecimento ou desconhecimento de termos relacionados ao desempenho e à eficiência do edifício;

iii. o interesse em melhorar o desempenho da edificação durante seu processo;

iv. a capacidade de tomar decisões de projeto ao escolher os resultados e o modo de análise da edificação;

v. os parâmetros de projeto definidos em cada fase do processo e os dados de entrada necessários para simulações termo-energéticas.

Proposição para estrutura de trabalho

A partir da análise anterior, e considerando a relação entre definição de parâmetros da edificação e dados de entrada de simulação, propõe-se uma estrutura de trabalho para a tomada de decisões de projeto com o objetivo de melhorar o desempenho térmico da edificação. Esta estrutura conta com a diferenciação de avaliações entre as fases de projeto anteriormente levantadas: concepção, estudo preliminar e anteprojeto.

A proposta de estrutura de trabalho tem como objetivo entender a aplicabilidade destes estudos em fases iniciais de projeto, tendo em vista que simulações de desempenho sem muitas definições podem induzir a erros. Além disso, com o desenvolvimento dessa estrutura de trabalho, pretende-se considerá-la como base para experimentos futuros, seja na inserção de simulações no ensino de desempenho térmico para os estudantes, sejam testes no desenvolvimento de projetos em escritórios de arquitetura ou por arquitetos autônomos.

A partir desta proposição de estrutura de trabalho pode-se compreender e organizar possíveis melhorias no ensino e no desenvolvimento de projeto a partir de dados coletados pelos próprios projetistas. Estes dados advindos dos arquitetos podem estreitar as duas disciplinas a partir da melhor compreensão de definições de projeto e de preferências na forma da análise de desempenho da edificação e, assim, incentivá-la. Além disso, pode-se compreender como estas ferramentas deveriam ser desenvolvidas para sua utilização ser mais recorrente.

\section{Resultados e discussão}

Analisou-se os parâmetros a partir das 72 respostas obtidas. A faixa etária dos entrevistados variou de 22 a 74 anos, porém, metade dos entrevistados tem até 30 anos de idade e $80 \%$ tem até 10 anos de formação.

Todas as análises de parâmetros bioclimáticos, de simulação e de definição de projeto nas próximas seções foram realizadas segundo sua relevância para determinada etapa 
de projeto. Para tanto, criou-se uma escala de relevância por diferenciação de cores, baseando-se em intervalos pré-definidos com base nos percentuais de respostas.

O Quadro 2 apresenta a escala de cor representativa, partindo do branco para parâmetros sem relevância para todos os entrevistados, até cores mais escuras com maior relevância. Assim, os Quadros 3, 4 e 5 se baseiam nessa escala de cor.

Quadro 2 - Legenda dos Quadros 3, $\mathbf{4}$ e $\mathbf{5}$ quanto à relevância para cada etapa de projeto.
\begin{tabular}{|c|c|c|c|c|}
\hline $\begin{array}{c}\text { Percentuais de respostas } \\
\text { obtidas }\end{array}$ & $\begin{array}{c}\text { Nível de relevância } \\
\text { associado aos } \\
\text { percentuais de } \\
\text { resposta }\end{array}$ & $\begin{array}{c}\text { Legenda de cores para as diferentes variáveis avaliadas } \\
\text { bioclimáticos }\end{array}$ & $\begin{array}{c}\text { Resultados de } \\
\text { projeto }\end{array}$ & $\begin{array}{c}\text { Parâmetros de } \\
\text { simulação }\end{array}$ \\
\hline $0 \%$ (nenhum voto) & Sem relevância & & & \\
\hline $0 \%<$ Votos $\leq 20 \%$ & Menor relevância & & & \\
\hline $20 \%<$ Votos $\leq 40 \%$ & & & & \\
\hline $40 \%<$ Votos $\leq 60 \%$ & Intermediário & & & \\
\hline $60 \%<$ Votos $\leq 80 \%$ & & & & \\
\hline $80 \%<$ Votos $\leq 100 \%$ & Maior relevância & & & \\
\hline
\end{tabular}

Fonte: os autores.

Deve-se considerar a possibilidade de algumas respostas estarem enviesadas por condições como a desejabilidade social (Social Desirability Bias). De acordo com Almiro (2017), esse viés pode ser entendido como a tendência de participantes em reportarem atitudes ou comportamentos com valores socialmente desejáveis a fim de satisfazerem sua necessidade de aprovação social. Essa é uma condição recorrente em estudos que envolvem seres humanos, e por isso é importante destacá-la em todas as análises que seguem.

\section{Parâmetros bioclimáticos e de desempenho já considerados}

Esta seção avalia os parâmetros bioclimáticos mais relevantes e o conhecimento sobre termos e normativas de desempenho térmico e de eficiência energética. O Quadro 3 apresenta um resumo das respostas obtidas para esta temática, e os parâmetros foram analisados segundo a escala criada no Quadro 2.

Quadro 3 - Levantamento de parâmetros bioclimáticos e de desempenho

\begin{tabular}{|c|c|c|c|c|c|c|c|c|c|c|}
\hline \multicolumn{11}{|c|}{ Parâmetros levantados } \\
\hline $\begin{array}{l}\text { Fase da elaboração do } \\
\text { projeto }\end{array}$ & 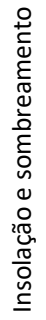 & 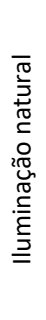 & 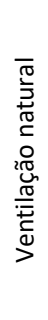 & ֻे & $\begin{array}{l}\frac{n}{\pi} \\
\frac{\pi}{2} \\
\frac{\pi}{\pi} \\
\frac{\pi}{2}\end{array}$ & 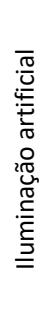 & 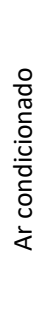 & 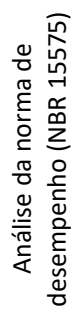 & 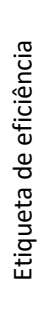 & 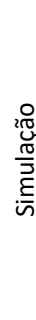 \\
\hline \multicolumn{11}{|l|}{ Concepção } \\
\hline \multicolumn{11}{|l|}{ Estudo preliminar } \\
\hline \multicolumn{11}{|l|}{ Anteprojeto } \\
\hline Não considero & & & & & & & & & & \\
\hline
\end{tabular}

É perceptível a grande relevância de análises de insolação, iluminação natural e ventilação natural para a etapa de concepção de projeto, e que segue com certo grau de relevância para as outras fases projetuais.

Essa condição expõe que alguns dos participantes tendem a responder o que consideram "correto" ou que o acreditam que os pesquisadores desejam como resposta. Visto isso, essa prática pode não ser não necessariamente o que eles acreditam ou aplicam em seu cotidiano. De todo modo, isso mostra interesse e 
preocupação com o comportamento passivo das edificações projetadas, ou ao menos certo conhecimento e entendimento da relevância deste tema.

Mas mesmo que esse seja um resultado interessante, nota-se pelos resultados obtidos na pergunta seguinte (Quadro 1) que, apesar da intenção de considerar esses aspectos na concepção do projeto, não há certeza que as ferramentas aplicadas nas avaliações são suficientes ou adequadas. Mais de $60 \%$ dos entrevistados reportaram testar a efetividade por meio do georreferenciamento do programa Google SketchUp, ou seja, por meio de testes a partir da visualização de luz e sombra. A ineficácia de testes se agrava a partir do segundo método mais utilizado, o manual, que engloba croquis, desenhos e maquetes físicas, como base de "teste" de quase metade dos entrevistados. Nota-se que os métodos utilizados de forma recorrente não têm base concreta de efetividade, ou seja, não há análise de eficácia da diretriz tomada para insolação, iluminação natural ou ventilação natural. Ou seja, mesmo que estes parâmetros já sejam incorporados no desenvolvimento de projeto, pouca precisão se tem quanto à análise crítica da diretriz tomada para supri-lo.

Agrava-se esta imprecisão ao perceber os resultados da seção que avaliou o conhecimento sobre pontos da área de desempenho térmico e eficiência energética de edificações. Nota-se, no Quadro 3, que parâmetros como a norma de desempenho de edificações, NBR 15575, e a etiqueta de eficiência energética são pouco relevantes durante o desenvolvimento dos projetos; inclusive, não são conhecidas por alguns dos participantes. O mesmo resultado é válido no caso da simulação computacional. Percebe-se no Quadro 4 mais adiante, em que uma parte dos entrevistados reporta não saber analisar dados como graus-hora de desconforto e carga térmica, que são parâmetros base utilizados em normativas e no método atual de etiquetagem de edificações. Em resumo, parâmetros bioclimáticos importantes têm grande relevância para definições de projeto, segundo reportam, mas os arquitetos não sabem se estas diretrizes estão ou não funcionando como esperado, ou ainda, os consideram de forma superficial.

Outro ponto importante, ainda no Quadro 3, é a definição de parâmetros relacionados ao consumo de ar condicionado e iluminação artificial. Sua relevância se dá em estágios mais avançados, aqui representado como o anteprojeto. Sabe-se que é a partir da escolha de diretrizes de ventilação natural, insolação e sombreamento desde a concepção de projeto que se pode reduzir o consumo final destes sistemas. Ainda que estes subsistemas não façam parte do escopo do projeto na maioria dos casos, ou que só sejam definidos após os projetos de instalação (que realmente têm relação muito mais estreita na fase de anteprojeto ou posterior), sua predição pode auxiliar o desenvolvimento de projeto. É a partir de seus resultados de carga térmica e consumo que se pode compreender a efetividade de uma diretriz traçada relacionada ao desempenho térmico do ambiente construído. Ao comparar resultados de diretrizes diferentes, pode-se compreender a influência destas na redução do consumo e da carga térmica, e assim, auxiliar na tomada de decisões do projeto. Com altos percentuais de horas em conforto, aliados à redução de carga térmica e consumo de resfriamento, a edificação se torna mais próxima da resiliência em relação ao clima.

Quanto aos outros parâmetros levantados no questionário nesta fase, como materiais de alto de desempenho e cores da edificação, novamente estão atrelados ao anteprojeto. Percebe-se aqui que o uso destes materiais se dá, em grande parte do tempo, como medida emergencial após a consolidação do projeto, reforçando a fundamentação. É possível, ainda, correlacionar este resultado com o distanciamento dos ensinos de desempenho térmico e de projeto, tendo em vista que o conhecimento de materiais e suas propriedades físicas não é aplicado nas decisões iniciais de projeto. 
Uma vez realizado o estudo do clima em que o edifício será inserido, já na concepção, medidas em relação à envoltória (neste caso, materiais) já deveriam ser préestabelecidas. Ressalta-se que o Brasil possui climas bem distintos e o uso de materiais de alto desempenho, ou mesmo composições de materiais diferentes a fim de melhorar o desempenho global da edificação, se faz necessário em alguns desses climas.

\section{Inserção de simulação termo-energética no processo}

Com base nos resultados anteriores, enfatiza-se a necessidade de algum tipo de teste eficaz de diretrizes durante o processo projetual, visto que dificilmente são realizados. Entretanto, é necessário compreender se é de interesse destes arquitetos a utilização de testes durante o seu processo criativo. Sendo assim, questionaram-se as preferências dos projetistas, tanto em relação à possível aplicação de simulação no seu processo projetual, quanto às suas preferencias sobre este método, caso afirmativo. A partir deste levantamento é possível não só compreender a ferramenta de maior interesse para os mesmos, mas também o próprio entendimento sobre o tema, suas variáveis e resultados.

Dentre os 72 entrevistados, apenas 2 não tiveram interesse em considerar outros parâmetros bioclimáticos durante o seu processo de projeto, mas apenas um deles por não achar importante. Dos 70 que têm interesse, 39 ( $54 \%$ dos 72 ) reportaram que, ou acham a informação de difícil compreensão, ou não têm muito conhecimento sobre o tema.

Como apontado anteriormente, 70 entrevistados responderam essa seção do questionário, tendo em vista seu interesse. Destes, 65 (93\% de 70) gostariam que a ferramenta de simulação fosse integrada ao ambiente de modelagem já utilizado durante as etapas de projeto, enfatizando a importância de que estas análises estejam imersas no desenvolvimento por meio de uma interoperabilidade entre programas que seja imperceptível. O Quadro 4 apresenta o resumo dos resultados obtidos quanto à preferência do resultado de simulação a ser analisado.

Quadro 4- Levantamento de resultados de simulação

\begin{tabular}{|c|c|c|c|c|c|c|c|c|}
\hline \multicolumn{9}{|c|}{ Parâmetros levantados } \\
\hline Fase da elaboração do projeto & 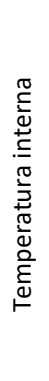 & 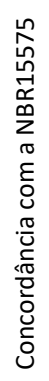 & 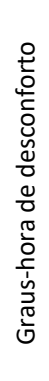 & 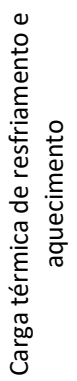 & 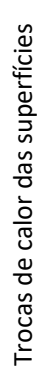 & 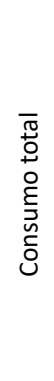 & 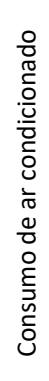 & 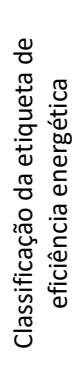 \\
\hline \multicolumn{9}{|l|}{ Concepção } \\
\hline \multicolumn{9}{|l|}{ Estudo preliminar } \\
\hline \multicolumn{9}{|l|}{ Anteprojeto } \\
\hline \multicolumn{9}{|l|}{ Não sei analisar esse dado } \\
\hline Não tenho interesse & & & & & & & & \\
\hline
\end{tabular}

Fonte: os autores.

Nota-se, aqui, maior relevância de análise no estudo preliminar de modo geral, com destaque para análise de temperaturas internas dos ambientes. Para esta etapa, os resultados que têm maior relação com temperaturas e trocas de calor são de maior relevância (em números absolutos de respostas), e por outro lado, dados de saída relacionados ao consumo da edificação são considerados de maior importância na fase mais avançada. Este resultado é interessante, ao considerar que as simulações 
realizadas no anteprojeto têm maior nível de detalhamento. E assim, como visto no Quadro 3, parâmetros importantes de consumo são definidos também nessa fase, como o projeto de iluminação artificial e de condicionamento de ar.

Ainda assim, é preocupante notar a diferença nos níveis de importância entre o Quadro 3 e o Quadro 4, no qual o Quadro 4 apresenta relevância de parâmetros quase homogênea para determinadas fases. Novamente questiona-se o entendimento sobre o tema. Em contrapartida, poucas respostas demonstraram desinteresse por determinado parâmetro, se comparadas com o número de respostas de ter interesse em incorporar em alguma fase de projeto.

É importante ressaltar, novamente, sobre os resultados de graus-hora de desconforto e de carga térmica, pois estes são os dois parâmetros com maiores avaliações de desconhecimento pelos entrevistados. Relacionam-se estes parâmetros com a sua utilização, que está vinculada ao desenvolvimento de normativas e de etiquetagem de eficiência energética de edificações. Ao passo que a classificação de eficiência energética também obteve resultados tanto de falta de interesse, como de desconhecimento da mesma, é possível associar este resultado com o desconhecimento dos termos desta classificação. Questiona-se aqui se, caso os parâmetros de classificação da etiqueta fossem mais adequados ao dia-a-dia de desenvolvimento de projeto, se esta seria mais facilmente inserida no processo e, talvez, fosse de conhecimento de um maior número de projetistas.

Não obstante, mesmo que apenas dois dos entrevistados tenham reportado que não gostariam de considerar mais parâmetros no processo, nota-se, para os demais participantes, que grande parte dos parâmetros têm pouca ou relevância intermediária. Em comparação às informações do Quadro 3, tem-se que os dados de insolação, ventilação natural e iluminação natural tiveram relevâncias bastante expressivas tanto para a concepção, quanto para o estudo preliminar. Novamente evidencia-se a superficialidade de análise destes fatores durante o desenvolvimento do projeto, e consequentemente, os objetivos traçados não são alcançados. Seja porque a ventilação natural não ocorre como esperado, ou a insolação se dá de forma diferente e a iluminação natural pode não ser suficiente.

Outro ponto que aqui prevalece é que, pelo menos um dos entrevistados não soube analisar algum dos termos apresentados. O desconhecimento sobre temperaturas e trocas de calor, que fazem parte do escopo de ensino do projetista durante sua formação, é preocupante e reforça, novamente, o distanciamento da prática projetual e de ensino de desempenho térmico.

Já a fase de concepção possui, segundo o Quadro 4, relevâncias menores que a faixa intermediária para todos os parâmetros. Ao correlacionar estes resultados com os resultados obtidos sobre as fases de definição de projeto, apresentados no Quadro 5 , percebe-se a importância da concepção para as análises iniciais de desempenho da edificação para a tomada de decisões. Parâmetros importantes como a análise do entorno, que altera a disponibilidade de luz, calor e vento; definições de orientações do volume da edificação e dos ambientes, que se relacionam com o ganho ou não de calor e vento no ambiente interno; a volumetria no lote projetado, que está ligada com a metragem quadrada e o tamanho das superfícies que possuem contato com o meio externo; e o número de ambientes e, consequentemente, a relação de volume entre estes, que interfere novamente tanto nas trocas de calor destes ambientes entre si, quanto com o ambiente externo; têm grande relevância nesta fase tão inicial. Neste caso, os testes podem comprovar se as decisões tomadas são ou não coerentes com aquele local e projeto. 
A partir do Quadro 5 pode-se, também, notar a relevância de definição de parâmetros agregadas às dimensões do projeto no estudo preliminar. Esses parâmetros conectamse com os dados de entrada importantes para simulações de desempenho, agravando, então, que os resultados destas análises poderiam influenciar de forma positiva a determinação das dimensões. Por fim, como esperado, os parâmetros levantados têm relevância intermediária ou baixa para a fase de anteprojeto, reforçando ainda mais a importância de análise do projeto anterior à esta etapa.

Quadro 5 - Levantamento de parâmetros de projeto

\begin{tabular}{|c|c|c|c|c|c|c|c|c|c|c|c|c|c|}
\hline \multicolumn{14}{|c|}{ Parâmetros levantados } \\
\hline Fase da elaboração do projeto & 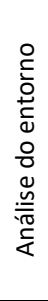 & 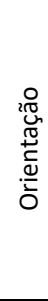 & 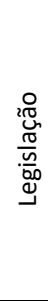 & $\begin{array}{l}\frac{0}{2} \\
\frac{1}{2} \\
\frac{E}{J} \\
\frac{\partial}{0}\end{array}$ & 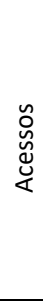 & 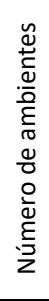 & 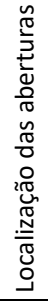 & 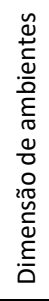 & 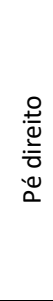 & $\begin{array}{l}\frac{n}{\pi} \\
\frac{\pi}{2} \\
\frac{\pi}{2} \\
\sum\end{array}$ & 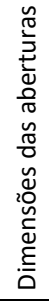 & 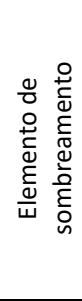 & రั \\
\hline \multicolumn{14}{|l|}{ Concepção } \\
\hline \multicolumn{14}{|l|}{ Estudo preliminar } \\
\hline Anteprojeto & & & & & & & & & & & & & \\
\hline
\end{tabular}

Fonte: os autores.

Após a seleção dos resultados mais interessantes para cada etapa, os entrevistados reportaram como gostariam de analisá-los. Constatou-se que $99 \%$ deles têm interesse em analisá-los por diferenciação de cores entre ambientes e superfícies diretamente no programa de desenvolvimento do projeto, a fim de comparar trocas de calor de diferentes superfícies e diferentes temperaturas entre ambientes. Pouco mais de 30\% gostaria, também, de avaliar por gráficos anuais de variação de valores, além da diferenciação de cores. Análises numéricas e por escala de eficiência e consumo tiveram relevância inferior a 30\% dos entrevistados.

Mesmo com todas estas escolhas, quase $70 \%$ dos entrevistados sente a necessidade de obter uma resposta do programa sobre o que fazer para melhorar o desempenho da edificação. Infere-se novamente a pouca ou nenhuma autonomia dos projetistas em relação à essa problemática. A insegurança pode estar relacionada a diversos fatores, mas como já citado anteriormente, há grande distanciamento das práticas de ensino de projeto e de desempenho térmico já na sua formação. Mesmo que estes aprendam sobre as variáveis e os termos relacionados ao desempenho do edifício, a aplicação no desenvolvimento do projeto não ocorre já na formação do projetista. Desta forma, o aluno não desenvolve, desde o início, o senso crítico sobre as suas decisões de projeto e, mesmo ao receber um resultado escolhido, pela falta de prática e de conhecimento, não sabe analisá-lo e, consequentemente, não o incorpora. Isso porque as práticas de desenvolvimento de projeto na academia não incentivam estas análises desde o momento inicial, e se incentivam, é de forma superficial, assim apresentado nas análises do Quadro 3.

\section{Proposta para estrutura de trabalho}

A partir dos resultados apresentados nas seções anteriores, organiza-se a proposta de estrutura de trabalho para o desenvolvimento do projeto de acordo com suas fases. Pode-se relacionar as definições conceituais, volumétricas e de massa à concepção, e estudos de definições importantes da dimensão dessa volumetria ao estudo preliminar. Desta forma, a proposta de estrutura de trabalho com implementação de estudos de desempenho térmico parte da análise de definição de parâmetros segundo essas etapas, e relaciona-os às análises bioclimáticas e aos dados de entrada em simulações. 
Como apresentado, a fase de concepção é determinante ao definir áreas expostas ao exterior, paredes, coberturas, contato com o solo, condicionantes de implantação e orientações. Já o posicionamento de aberturas, os materiais da envoltória e o dimensionamento da edificação de modo geral atrela-se ao estudo preliminar. Por fim, apesar de não haver grande relevância de fatores para o anteprojeto, há o refinamento de todos os anteriormente apresentados. A partir da definição de parâmetros e sua correlação com a fase de projeto, estipulam-se as análises bioclimáticas ou de desempenho térmico para cada uma destas.

Atrelam-se análises bioclimáticas à fase de concepção, visto resultados anteriormente apresentados de análises de sol e vento já nesta fase. Porém, intensifica-se a veracidade destes pontos sugerindo a análise consolidada a partir de arquivos climáticos, nos quais permitem verificação da disponibilidade de ventos e de sol, além de suas relações com temperaturas externas durante determinada estação do ano. Além disso, essas análises mais concretas já levam em consideração um estudo prévio do clima e das diretrizes necessárias, mas ao mesmo tempo inserindo-as no contexto a ser projetado, verificando a disponibilidade de usufruir das diretrizes. Dado que o contexto do entorno pode já sombrear um local, ou ao contrário, necessitar de altos índices de radiação solar porém o entorno não permitir e ser necessário partir para outras diretrizes. Essas práticas já na concepção permitem que os parâmetros definidos nessa fase, como volumetria, implantação e orientações solares das fachadas, já sejam otimizados segundo o clima.

Reforça-se que não houve grande interesse em análise de resultados de simulação para a fase de concepção, como apresentado no Quadro 4. Em contrapartida, observa-se que há pouco ou nenhum conhecimento sobre as influências do clima na edificação projetada. Tendo isso em vista, supõe-se que o entendimento de fluxo de calor nas superfícies, ou das temperaturas superficiais, ou mesmo de exposição à radiação ou à disponibilidade de ventos do determinado local, analisando o entorno inserido, podem guiar as decisões de projeto ainda na concepção.

Já no estudo preliminar, estas diretrizes podem ser refinadas e efetivadas por meio da simulação do desempenho térmico da edificação. Assim, os parâmetros de projeto definidos nessa fase podem ser otimizados. No Quadro 5 destacaram-se as localizações e dimensões das aberturas, dos ambientes, do pé direito e a escolha de materiais no estudo preliminar. Apesar de reforçar, novamente, que a escolha de materiais deve ser iniciada na concepção atrelada às análises do clima, nesta fase este parâmetro passa a ser efetivamente avaliado segundo seu bom desempenho para o clima. É notável que estes parâmetros podem ser otimizados por simulações paramétricas, visto que as dimensões mais concretas de diversos fatores da edificação passam a ser definidas. Assim, resgatando da fundamentação sobre processo projetual, o embasamento da tomada de decisões de projeto por meio da busca de solução de problemas, refletindo sobre a análise, síntese e avaliação desta solução, nota-se que a simulação vem ao encontro desta prática. Isso uma vez que, por meio de simulações iniciais, passa-se a buscar soluções melhores ao projeto, sendo a problemática inicial a redução da carga térmica ou do consumo de resfriamento da primeira simulação.

Este fato respalda as análises em relação ao Quadro 4, visto que os entrevistados optaram em receber resultados de simulação no estudo preliminar, de forma geral. Assim, sugerem-se pequenas análises de sensibilidade nesta fase, a fim de guiar o projetista nas suas escolhas de projeto a partir de um parâmetro final de análise. A partir da diferenciação dos resultados de uma simulação para a outra, com a constante alteração de parâmetros, que se pode chegar a resultados mais próximos do ideal para aquele contexto. Além disso, pode-se perceber quais diretrizes são as mais efetivas, uma vez que, sem respostas de simulações, pode-se acreditar que determinado 
parâmetro tem mais influência que outro no desempenho final da edificação, mas não condizer com a realidade.

Ao refinar as definições de projeto durante o anteprojeto, propõe-se uma simulação mais detalhada, precisa e crítica, como já realizada em alguns casos. O Quadro 3 ressalta as definições atreladas diretamente ao consumo da edificação nessa fase: iluminação artificial e condicionamento de ar. Já no Quadro 4 apresenta-se que dados de consumo energético (tanto total da edificação quanto de resfriamento) e a classificação de eficiência da edificação são métricas relevantes. Novamente, destaca-se a relevância baixa de definições de projeto durante essa fase, conforme apresentado no Quadro 5. Por isso, a simulação detalhada é ideal para este caso: os parâmetros de projeto não têm mais grandes alterações; as definições de subsistemas da edificação são de grande relevância; e ainda, os resultados de simulação mais esperados estão intrinsecamente ligados às definições de subsistemas: o consumo e a classificação de eficiência.

Para tanto, considera-se a integração de equipes de projetistas a equipes de consultores ou simuladores profissionais. Não se espera que os projetistas adquiram conhecimento avançado sobre as simulações, visto que este é um tema denso. Assim, a presença de um simulador para este detalhamento é imprescindível. Ajustes finais e precisos em relação ao projeto já consolidado, seja ainda de materiais ou já de instalações, podem ser concebidos nesta etapa a partir da composição da edificação muito mais adequada.

Por fim, os autores acreditam que, mesmo com as definições de materiais e cores com o caráter de maior relevância no estudo preliminar, como mostram os resultados do questionário aplicado, é imprescindível considerá-los em todo o processo. Desde as análises na fase de concepção, tendo em vista que estes fatores são de grande influência nas trocas térmicas entre o meio externo e interno, além de serem primordiais para a análise da influência do clima nas superfícies da envoltória da edificação.

Partindo das relações anteriormente apontadas, a Figura 1 resume a proposta de estrutura de trabalho com a inserção de simulações de desempenho térmico durante o processo de projeto.

Figura 1 - Estrutura de trabalho
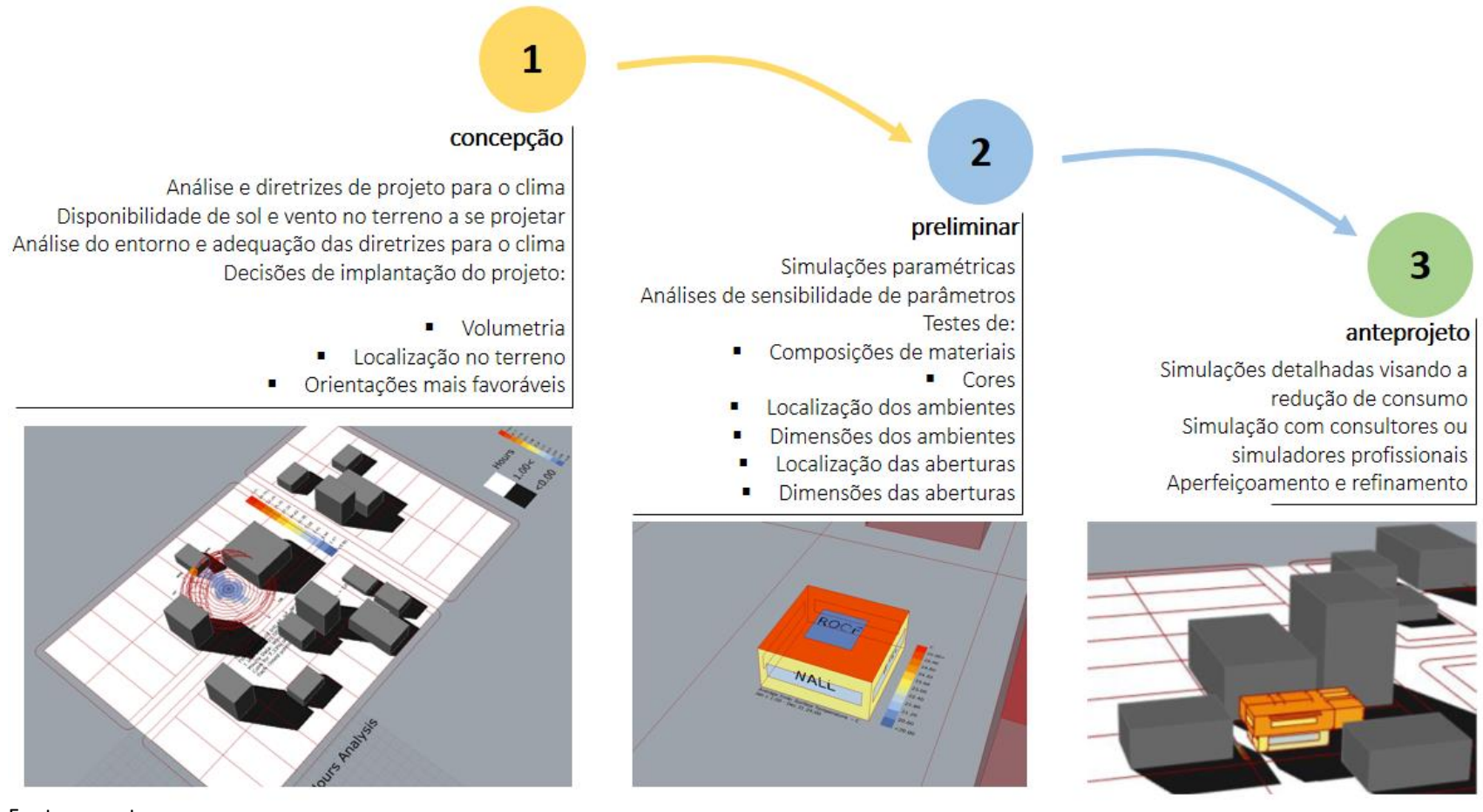

Fonte: os autores. 


\section{Conclusão}

A partir do desenvolvimento do trabalho foi possível traçar padrões de definições de projeto vinculadas às fases de desenvolvimento inicial. Com base nesses resultados, analisou-se a compreensão dos arquitetos entrevistados sobre o desempenho térmico em edificações e a importância que se dá para esse tema no mercado brasileiro atual. Verificou-se, também, o interesse destes sobre a utilização de simulações de desempenho durante o processo e seus principais motivos. Percebe-se interesse por parte dos entrevistados, não apenas em implementações futuras, mas também considerando-se algumas análises que são empregadas atualmente. Entretanto, a avaliação das respostas evidenciou que essas análises já realizadas não necessariamente condizem com a realidade, uma vez que são desenvolvidas em programas ou por métodos pouco precisos. Ainda assim, percebe-se que os entrevistados dão importância a este tema durante todas as fases de projeto.

Devido aos resultados, que mostraram incertezas nos testes de diretrizes relacionadas ao desempenho térmico da edificação, percebe-se a necessidade de uma proposta para estrutura de trabalho integrando análises mais concretas ao desenvolvimento do projeto. Nota-se grande potencial de análises térmicas logo nas decisões iniciais em contraposição à fase de anteprojeto.

A fase de concepção define áreas expostas ao exterior, paredes, coberturas, contato com o solo, condicionantes de implantação e orientações. Ao mesmo tempo, não houve grande interesse de resultados de simulação para esta fase, mesmo com análises de diretrizes bioclimáticas sendo de grande importância no início de projeto. Visto isso, sugeriu-se uma estrutura de trabalho a fim de integrar critérios de desempenho térmico ao processo de projeto de edificações. Esta estrutura baseia-se em análises do clima, do entorno, da implantação de projeto e de suas exposições solares e de vento por meio de estudos do arquivo climático da região. Ressalta-se que o uso de arquivos climáticos permite maior compreensão do clima local, bem a disponibilidade de sol e vento, além das temperaturas externas.

No que diz respeito ao dimensionamento da edificação, de modo geral, define-se durante o estudo preliminar. É também nesse estágio que se consideram grande parte dos resultados de simulação termo-energética, desde temperaturas internas à carga térmica e consumo. Relacionando estes dois resultados, vê-se potencial da inserção de simulações paramétricas e de sensibilidade de parâmetros nesta fase. Assim, busca-se a otimização do projeto por meio de análise, síntese e avaliação das soluções propostas e refletidas pelos projetistas.

Por fim, no anteprojeto, há o refinamento de todos os anteriormente apresentados. Neste caso, ressalta-se a importância da integração entre os projetistas e simuladores profissionais. Dado que grande parte dos parâmetros de projeto não sofre alterações significativas nessa fase, e sim, instalações relacionadas à eficiência energética da edificação, aqui mencionadas iluminação artificial e condicionamento de ar. Dados de consumo e de classificação da etiqueta de eficiência passam a ser resultados de simulação de interesse dos entrevistados, e une todos os outros pontos apresentados para essa fase.

Ainda assim, sugere-se na estrutura de trabalho que parâmetros como materiais e cores sejam considerados desde a concepção, a fim de incentivar as escolhas do projetista relacionando-os com a conformação do projeto e baseando sua escolha em valores concretos. 
Este potencial foi mostrado considerando a implementação de diferentes análises durante estas fases de projeto: desde análises externas à edificação, considerando a inserção no clima e no entorno, passando por simulações de análises paramétricas e de sensibilidade de decisões de projeto, para então atingir simulações mais detalhadas após grandes definições de projeto.

Criou-se uma proposta de estrutura de trabalho a fim de facilitar o desenvolvimento de projeto. Pretende-se testar a efetividade desta estrutura de trabalho, tanto no desenvolvimento de projetos reais, quanto no ensino de alunos de graduação a partir do entendimento destes parâmetros por meio de simulações de desempenho. A criação da estrutura teve como objetivo a organização de um fluxo de trabalho que considere essas análises, mas que também una as duas temáticas tratadas neste artigo: o desenvolvimento de projeto às análises de desempenho térmico das edificações. Futuramente, pretende-se testar estes resultados obtidos e aperfeiçoar esta estrutura de trabalho, além de quantificar reduções possíveis alcançadas por meio destas análises.

\title{
Agradecimentos
}

O presente trabalho foi realizado com o apoio da Coordenação de Aperfeiçoamento de Pessoal de Nível Superior Brasil (CAPES) - Processo No. 88882.438468/2019-01.

\section{Notas}

(1) ENERGYPLUS. EnergyPlus, [s.d.]. Disponível em: https://energyplus.net/. Acesso em: out. 2019

(2) Questionário aprovado pelo Comitê de Ética em Pesquisa com Seres Humanos - CEPSH/UFSC. CAAE: 12372919.5.0000.0121. Número do parecer: 3.400.807.

\section{Referências}

\begin{abstract}
AIA - THE AMERICAN INSTITUTE OF ARCHITECTS. Architect's Guide to Building Performance - Integrating performance simulation in the design process. [s.l: s.n.]. Disponível em:

http://content.aia.org/sites/default/files/2019-06/Energy_Design_Modeling_Guide_v4.pdf. Acesso em: jul. 2019.
\end{abstract}

ALMIRO, Pedro Armelim. Uma nota sobre a desejabilidade social e o enviesamento de respostas. Avaliação

Psicológica, v. 16, n. 3, jul. 2017. Disponível em: http://dx.doi.org/10.15689/ap.2017.1603.ed. Acesso em: out. 2019.

BLEIL DE SOUZA, Clarice. Studies into the use of building thermal physics to inform design decision making. Automation in Construction, [s. I.], v. 30, p. 81-93, 2013. DOI: http://dx.doi.org/10.1016/j.autcon.2012.11.026

BLEIL DE SOUZA, Clarice; TUCKER, Simon. Thermal simulation software outputs: what do building designers propose? In: CONFERENCE OF INTERNATIONAL BUILDING PERFORMANCE SIMULATION ASSOCIATION, 13., 2013, Chambéry, Proceedings [... ]. Chambéry: IBPSA, 2013, p. 468-475.

CAU/BR - CONSELHO DE ARQUITETURA E URBANISMO DO BRASIL. Módulo I: Renumeração do projeto arquitetônico de edificações. Brasília: CAU/BR, 2014. Disponível em: https://honorario.caubr.gov.br/doc/TAB-livro1final.pdf. Acesso em: jun. 2021.

CHERRY, K. The Hawthorne Effect and Behavioral Studies. Verywellmind, Basics, out 2020.Disponível em: https://www.verywellmind.com/what-is-the-hawthorne-effect-2795234. Acesso em: jun. 2021.

ELBELTAGI, Emad et al. Visualized strategy for predicting buildings energy consumption during early design stage using parametric analysis. Journal of Building Engineering, [s. I.], v. 13, n. July, p. 127-136, 2017. DOI:

http://dx.doi.org/10.1016/j.jobe.2017.07.012. 
EPE - EMPRESA DE PESQUISA ENERGÉTICA. Balanço energético nacional: Ano base 2018. Empresa de Pesquisa Energética, [s. I.], p. 67, 2019. Disponível em: https://www.epe.gov.br/sites-pt/publicacoes-dadosabertos/publicacoes/PublicacoesArquivos/publicacao-377/topico-494/BEN\%202019\%20Completo\%20WEB.pdf. Acesso em: jul. 2019.

IEA - INTERNATIONAL ENERGY AGENCY. The Future of Cooling. [s.I], 2018. Disponível em: https://www.iea.org/reports/the-future-of-cooling. Acesso em: jun. 2021.

LAWSON, Brian. Como arquitetos e designers pensam. 1.ed. São Paulo: Editora Oficina de Textos, 2011.

MACIEL, Alexandra Albuquerque. Integração de Conceitos Bioclimáticos ao Projeto Arquitetônico. 2006. Tese (doutorado) - Universidade Federal de Santa Catarina, Centro Tecnológico. Programa de Pós-Graduação em Engenharia Civil, Florianópolis, 2006. Disponível em: https://repositorio.ufsc.br/xmlui/handle/123456789/88974. Acesso em: jul. 2019

MITCHELL, William J. A Lógica da Arquitetura. 1.ed. Campinas: Editora Unicamp, 2009.

NEMBRINI, Julien; SAMBERGER, Steffen; LABELLE, Guillaume. Parametric scripting for early design performance simulation. Energy and Buildings, [s. I.], v. 68, n. PART C, p. 786-798, 2014. DOI:

http://dx.doi.org/10.1016/j.enbuild.2013.09.044

$\varnothing S T E R G A ̊ R D$, Torben; JENSEN, Rasmus L.; MAAGAARD, Steffen E. Building simulations supporting decision making in early design - A review. Renewable and Sustainable Energy Reviews, [s. I.], v. 61, p. 187-201, 2016. DOI:

http://dx.doi.org/10.1016/j.rser.2016.03.045

SAMUELSON, Holly et al. Parametric energy simulation in early design: High-rise residential buildings in urban contexts. Building and Environment, [s. I.], v. 101, p. 19-31, 2016. DOI:

http://dx.doi.org/10.1016/j.buildenv.2016.02.018

SHI, Xing et al. A review on building energy efficient design optimization from the perspective of architects. Renewable and Sustainable Energy Reviews, [s. I.], v. 65, p. 872-884, 2016. DOI:

http://dx.doi.org/10.1016/j.rser.2016.07.050

\footnotetext{
${ }^{1}$ Larissa Pereira de Souza

Arquiteta e Urbanista. Mestre em Arquitetura e Urbanismo. Pós-mestrado em andamento em Engenharia Civil pela Universidade Federal de Santa Catarina. Endereço postal: Departamento de Engenharia Civil, Centro Tecnológico, Campus Trindade, Universidade Federal de Santa Catarina, Florianópolis, Santa Catarina - Brasil. CEP 88040-900
}

\section{${ }^{2}$ Mateus Vinícius Bavaresco}

Engenheiro Civil. Mestre em Engenharia Civil. Doutorado em andamento em Engenharia Civil pela Universidade Federal de Santa Catarina. Endereço postal: Departamento de Engenharia Civil, Centro Tecnológico, Campus Trindade, Universidade Federal de Santa Catarina, Florianópolis, Santa Catarina - Brasil. CEP 88040-900

\section{${ }^{3}$ Carlos Eduardo Verzola Vaz}

Arquiteto e Urbanista. Doutor em Engenharia Civil. Professor Titular na Universidade Federal de Santa Catarina, Centro Tecnológico, Departamento de Arquitetura e Urbanismo. Endereço postal: Departamento de Arquitetura e Urbanismo, Centro Tecnológico, Campus Trindade, Universidade Federal de Santa Catarina, Florianópolis, Santa Catarina - Brasil. CEP 88040-970

\section{${ }^{4}$ Roberto Lamberts}

Engenheiro Civil. Doutor em Engenharia Civil. Professor Titular na Universidade Federal de Santa Catarina, Centro Tecnológico, Departamento de Engenharia Civil. Endereço postal: Departamento de Engenharia Civil, Centro Tecnológico, Campus Trindade, Universidade Federal de Santa Catarina, Florianópolis, Santa Catarina - Brasil. CEP 88040-900 